I do not share their pessimism with regard to staffing since I feel that a multidisciplinary approach to sexual matters will appeal to a new generation of doctors, particularly if abortion services were part and parcel of a unified family planning service with the problems of contraception, sterilization, and sexual difficulties well represented.

The problems are complex but since there is public demand, it is our duty to give carefully thought-out advice. If a new specialty is needed should the medical profession demur; has there ever been a time that a new challenge has been ignored successfully?-I am, etc.,

London N.9

\section{J. D. WILLIAMsoN}

\section{Sex and the Single Girl}

SIR,-Dr. J. Campbell Murdoch (22 July, p. 235) is right to criticize Drs. C. McCance and D. J. Hall (17 June, p. 694) for saying that a contraceptive service should be "morally uncommitted," but he is right for the wrong reason. He is right to say that a doctor who leaves his standards behind him becomes a danger to himself and to others, but he is wrong to imply that moral standards and a sense of commitment are the prerogative of those who believe in God.

Surely, a doctor has both moral standards and a sense of commitment if his words and actions are based on his own beliefs in what is in the best interests of his patient. The doctor, however, must be aware of the consequences of his action: what is the effect upon the patient? Is the patient filled with a sense of beatification comparable to that in the doctor at the end of his homily?

According to our age/sex register, there are over 4,000 girls in their twenties and thirties in our group practice: the area consists largely of large houses divided up into flats. It is our experience that the alternative to contraception is not continence but pregnancy. If a girl is advised against contraception she might go to another doctor or to the F.P.A. or she might risk pregnancy by using the "safe" period or coitus interruptus. If the girl intended to be continent then it is unlikely that she would have asked for contraception in the first place, and, furthermore, our experience would corroborate the findings from Aberdeen that many girls seek contraception after first intercourse.

Thus, advice against contraception is given too late and if heeded will cause guilt (which is the most damaging and far-reaching of all iatrogenic diseases) on the one hand or pregnancy on the other.-We are, etc.,

ROBERT LEFEVER

TOM TREVELYAN

London S.W.7 JOHN WEST

\section{A Virus from Epidemic Vomiting Disease}

SIR,-The authors of this excellent paper (8 July, p. 86) rightly state that the commonest abdominal symptom is a feeling of distension. May $I$ add that $x$-rays of the abdomen taken at this stage show considerable gaeseous distension confined to the transverse colon in the supine position. The gas would shift by its buoyancy into the ascending or descending colon in left or right recumbency. Unlike gastroenteritis caused by other pathogens, fluid levels in the colon are absent or insignificant. There is probably a causal relationship between the two phenomena, the excess gas in the transverse colon being responsible for the feeling of epigastric distension.

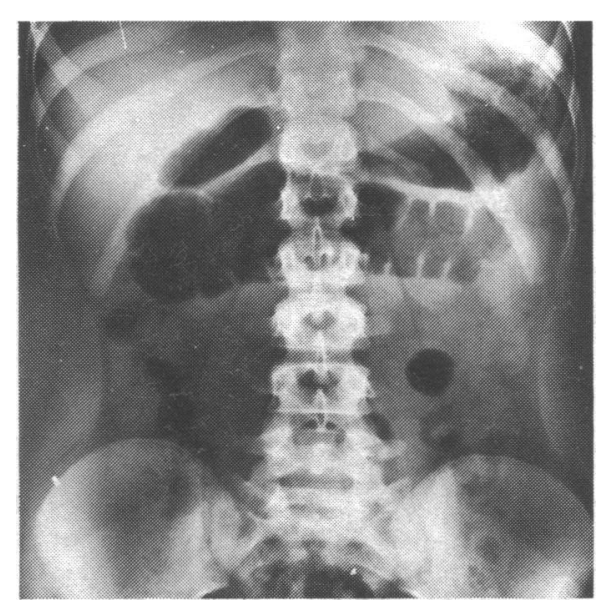

In hospital practice these cases are often referred to the $x$-ray department under the clinical suspicion of appendicitis in children or of pancreatitis in adults. The picture is sufficiently characteristic for the radiologist to suggest that epidemic vomiting disease might be taken into consideration in the differential diagnosis (Fig.).-I am, etc.,

X-ray Department,

St. George's Hosp
London S.w.1 Hajdu, N., Rénnion Internationale de Radiologie
Pédiatrique, 1963, Abstract 37 .

\section{Women Returning to Medicine}

SIR, - No doubt many readers will have read with interest the article in The Times "Women's Role in Medicine" (14 June) giving an account of the existing part-time, postgraduate training arrangements custombuilt to fit each woman's needs. We refer to Dr. Rosemary Rue's scheme in Oxford and Dr. Michael Essex-Lopestri's scheme in the South-west Metropolitan Region.

Now that Sir Keith Joseph has announced his women doctor's retainer scheme (17 June, p. 723), many women may feel a strong urge to take advantage of it, but are fearful to embark least they are unable to cope in the event of some domestic crisis. Crèches, play groups, and other such services are valueless when your child falls ill

In Leeds we now have the answer to this problem in the form of the Family Emergency Association. This organization, which has been running successfully since 1969 , is a mutual members club, and is legally recognized by the Town Clerk. (A mutual members club has two kinds of membersmutual members and donor members. The former are those who anticipate a need for help, though they can, if they wish, also provide help at other times; the latter provide help requested. We have not yet failed any member who required a "substitute mum" in an emergency. We feel that there must be many women medical graduates in Leeds who would gladly take advantage of these very good retraining schemes if they also had an insurance against the event of a domestic crisis.
It is for this reason that we wish to draw their attention to the existence of this service, and prevent them from letting splendid opportunities for retraining pass them by.We are, etc.,

\section{E. A. Colvinle}

J. WENBAN

Leeds

Platelet Adhesion and Aggregation

SIR,-Your leading articles must be factually correct, but when talking about platelet embolism and platelet aggregation and adhesion to glass you state that "these two properties appear to be identical" (8 July, p. 67). Most workers in the field would insist that you are wrong. It is true that in Glanzmann's thrombasthenia both platelet aggregation and adhesion to glass are abnormal. However, it is also generally accepted that in von Willebrand's disease platelet retention in a glass bead column is markedly decreased, and this test certainly involves platelet adhesion to glass. Platelet aggregation however is strictly normal. Contrarwise, immediately after two major operations, for example, platelet aggregation relative to the preoperative level is decreased but retention in the glass bead column is increased. 1 Thus these tests can vary independently, and this must mean that although perhaps some properties are shared, nevertheless some quite different mechanisms must operate. This at least is established even if full details of these two processes are still unknown.-I am, etc.,

\section{J. R. O'BRIEN}

Portsmouth and Isle of Wight Pathological Service, St. Mary's Hospital,

1 O'Brien, J. R., Etherington, M., Jamieson, S., and Klaber, $M$. 'R. Lancet, 1972, 1, 1302.

\section{Cytology in General Practice}

SIR,-Dr. B. Scaife and his colleagues $(22$ July, p. 200) describe a model for screening a busy industrial practice for precancerous conditions of the cervix. They are to be congratulated in reaching almost $90 \%$ of patients considered to be at risk.

May I comment on English "resistance" to cytology tests? Recently, as part of a research project, I visited a large industrial firm in Birmingham in an attempt to find out why a repeat screening by cytology produced almost the same percentage of acceptance (less than $20 \%$ ). With my colleagues A. J. Lucas, general practitioner, and Margaret Attwood, head of the Ministry cytology school in this department, I attended a meeting arranged by the medical officer in charge of the health of an industrial complex with some 8,000 women employees. Women shop stewards discussed with us the reasons why employees continued to decline cytotests. Their reasons correspond to those given by $\mathrm{Dr}$. Scaife and his colleagues, namely that (pregnancy apart) English women suffer from a kind of shyness when the organs of reproduction are mentioned. The women shop stewards made the original suggestion that we should approach all husbands by letter, explaining the value of preventing cancer of the neck of the womb so that they might encourage their wives to take a "prevention test."

In the factory there were many women 